ORIGINAL ARTICLE

\title{
Management of thoracic empyema in childhood: does the pleural thickening matter?
}

\author{
B Satish, M Bunker, P Seddon
}

Arch Dis Child 2003;88:918-921

See end of article for authors' affiliations

.....................

Correspondence to: Dr P Seddon, Royal

Alexandra Hospital for Sick

Children, Dyke Road,

Brighton BNI 3JN, UKK

Accepted

24 October 2002

\begin{abstract}
Aims: To determine the clinical course and long term outcome of empyema treated without decortication.

Methods: Fourteen consecutive admissions to one hospital were studied; radiological resolution and lung function were subsequently followed. The children were aged 2-14 years. All were treated with intravenous antibiotics and chest drain only.

Results: All patients had extensive pleural thickening evident on chest $x$ ray examination at the time of discharge, which resolved entirely over a period of 2-16 months. Lung function was measured in 13 children, and showed no evidence of restrictive or obstructive deficit: mean (SD) values as per cent predicted for height were: forced expiratory volume in one second $\left(\mathrm{FEV}_{1}\right) 107.5(9.6)$, forced vital capacity (FVC) 95.5 (8.8), total lung capacity (TLC) 98.6 (20.7). Individual children all had values in the normal range (80-120 per cent predicted).

Conclusion: Results suggest that decortication is not necessary in children to prevent long term problems with pleural thickening, and should be undertaken on the basis of the clinical picture (failure of fever resolution), rather than radiological appearance.
\end{abstract}

$\mathrm{T}$ management of thoracic empyema in children continues to evoke controversies from the past five decades. ${ }^{1-3}$ Treatment options include antibiotics alone or in combination with thoracentesis, ${ }^{45}$ tube thoracostomy (chest drain), ${ }^{16-8}$ intrapleural fibrinolytics, ${ }^{910}$ thoracoscopy, ${ }^{11-14}$ and open decortication. ${ }^{35-18}$ Reported series illustrate the striking variability in therapeutic approach in different centres, but provide little evidence in establishing the ideal treatment. In the absence of good clinical evidence, the choice among these options tends to be dictated by institutional traditions, personal experiences, and biases

Debate about the role of surgical decortication (performing a thoracotomy to remove the "peel": thickened inflamed pleura with fibrinous deposits) is far from new. ${ }^{1}$ Practice varies widely, and the rate of this procedure in reported series has varied from $1 \%^{19}$ to $90 \% .^{3}$ This controversy has been reactivated recently by the publication of two series from tertiary centres ${ }^{318}$ advocating early open decortication and showing an excellent clinical outcome with this policy.

However, open decortication is an invasive procedure, leaving significant postoperative pain and a thoracotomy scar. Thoracoscopic decortication is less invasive, but leaves multiple smaller scars and requires prolonged general anaesthesia. There are essentially two arguments for carrying out these procedures. The first is that the organised fibrinous deposits which appear early in an empyema impede drainage from and antibiotic penetration into the pleural space, and therefore prevent the infection from resolving, hence delaying discharge. ${ }^{18}$ The second is that the inflammatory "peel" prevents the lung from re-expanding properly and causes long term restriction. ${ }^{20}$

The first situation should be evident clinically by failure of fever and systemic upset to resolve. The second situation can only be detected by careful follow up: use of this argument reflects extrapolation from adult experience, ${ }^{1}$ which may not be relevant to children. Series from tertiary hospitals introduce selection bias in favour of unresponsive cases, many of whom did not receive appropriate early management in the referring hospital. ${ }^{318}$ We were prompted to carry out this study by the conflict between these observations and our own experience in a busy, non-teaching hospital. Most childhood empyema series have reported the short term outcome only: the two studies reporting long term outcomes ${ }^{21}{ }^{22}$ have had considerable variability of initial management, incomplete follow up, and probably included cases of simple parapneumonic effusion. We planned to study the short term outcome and longer term consequences of managing childhood empyema actively with antibiotics and drainage only. Put simply, do children suffer prolonged morbidity or impaired lung function as a result of failure to remove the pleural thickening?

\section{PATIENTS AND METHODS}

We studied all children admitted over a 26 month period (January 1996 to March 1998) to the Royal Alexandra Children's Hospital with empyema, defined by the following criteria:

- Febrile illness with pneumonic consolidation at onset.

- Fluid in the pleural space on chest $x$ ray and ultrasound examination.

- Cloudy pleural fluid with pus cells and loculation on ultrasound.

Thus, all patients were in at least stage II of the American Thoracic Society classification of empyema, ${ }^{4}$ and cases of simple parapneumonic effusions were excluded. Children with pre-existing significant medical problems (for example, cerebral palsy) were also excluded.

During the study period, initial management for all patients with empyema at our institution was as follows:

(1) Intravenous broad spectrum, high dose antibiotics (amoxycillin with clavulanic acid or cefotaxime).

(2) Chest tube sited (optimal placement decided by ultrasound) under short general anaesthesia. Chest tubes

Abbreviations: $\mathrm{FEV}_{1}$, forced expiratory volume in one second; $\mathrm{FVC}$, forced vital capacity; MMEF, maximal mid-expiratory flow; RV, residual volume; TLC, total lung capacity 


\begin{tabular}{|c|c|c|c|c|c|c|c|c|}
\hline $\begin{array}{l}\text { Patient } \\
\text { no. }\end{array}$ & $\begin{array}{l}\text { Time to radiological } \\
\text { resolution (mth) }\end{array}$ & $\begin{array}{l}\mathrm{FEV}_{1} \\
\text { (\% predicted) }\end{array}$ & $\begin{array}{l}\mathrm{MMEF}_{25-75} \\
\text { (\% predicted) }\end{array}$ & $\begin{array}{l}\text { FVC } \\
\text { (\% predicted) }\end{array}$ & $\begin{array}{l}\mathrm{FEV}_{1} / \mathrm{FVC} \\
(\%)\end{array}$ & $\begin{array}{l}\text { RV } \\
\text { (\% predicted) }\end{array}$ & $\begin{array}{l}\text { TLC } \\
\text { (\% predicted) }\end{array}$ & $\begin{array}{l}\text { RV/TLC } \\
(\%)\end{array}$ \\
\hline 1 & 2 & 110.7 & 90.7 & 108.6 & 97 & 113.9 & 101.2 & 111.2 \\
\hline 2 & 16 & 89.6 & 91.1 & 83.6 & 97.8 & 108.2 & 123.7 & 168.3 \\
\hline 3 & 3 & 101.9 & 96.8 & 88 & 112.9 & 115.9 & 90 & 131.1 \\
\hline 4 & 3 & 93.1 & 70 & 83.9 & 112.5 & 191.2 & 98.9 & 194.8 \\
\hline 5 & 6 & 104.7 & 115 & 107.8 & 97.7 & 193.9 & 152.9 & 134.7 \\
\hline 6 & 2 & 117.2 & 159.3 & 95.5 & 117.1 & 59.7 & 87.4 & 70.9 \\
\hline 7 & 2 & 108.7 & 111.3 & 99.8 & 95.35 & 98.4 & 85.2 & 114.4 \\
\hline 8 & 2 & 121.4 & 115.3 & 105.4 & 109.5 & 128.4 & 74.5 & 135.6 \\
\hline 9 & 3 & 112.4 & 115.1 & 93.2 & 114.5 & 179.5 & 104.3 & 168.5 \\
\hline 10 & 2 & 102.2 & 94.3 & 91.2 & 95.17 & 164.9 & 88.2 & 191.8 \\
\hline 11 & 2 & 120.9 & 129.1 & 99.6 & 98.4 & 157.2 & 106.1 & 143.2 \\
\hline 12 & 2 & 109.5 & 112.4 & 99.7 & 91.8 & 77.9 & 87.8 & 89.6 \\
\hline 13 & 6 & 104.8 & 99.8 & 85.3 & 98.3 & 80.5 & 82 & 96.5 \\
\hline 14 & 1 & - & - & - & - & - & - & - \\
\hline Mean & 3.71 & 107.4 & 107.7 & 95.5 & 102.9 & 128.4 & 98.6 & 134.6 \\
\hline SD & 3.83 & 9.6 & 21.7 & 8.8 & 8.8 & 44.9 & 20.6 & 38.4 \\
\hline Median & 2 & 108.7 & 111.3 & 95.5 & 98.3 & 115.9 & 90.0 & 134.7 \\
\hline
\end{tabular}

(Argyle FG 18-20) were inserted by a paediatric surgeon through a small $(1-2 \mathrm{~cm})$ incision after a finger sweep.

Subsequent management, including choice and duration of antibiotics, and timing of chest tube removal, was determined for the individual child by the team managing on the basis of clinical progress and culture results.

\section{Clinical data}

Demographic data, and clinical information on the inpatient course and management of the children were collected retrospectively from the case notes, microbiology records, and chest radiographs using a standard proforma. Chest radiographs were performed at follow up outpatient visits until the opacities had resolved.

\section{Lung function testing}

All children over 5 years of age were asked to attend for pulmonary function testing between 3 and 24 months after discharge. Measurements were made using a pneumotachograph based spirometer and body plethysmograph (MasterLab, Jaeger, Würzburg). Forced vital capacity (FVC), forced expiratory volume in the first second $\left(\mathrm{FEV}_{1}\right)$, maximal mid-expiratory flow $\left(\mathrm{MMEF}_{25-75 \%}\right)$, total lung capacity (TLC), and residual volume (RV) were measured and expressed as percentage of the predicted values for height (using normal values of Zapletal and colleagues ${ }^{23}$ ).

\section{RESULTS}

Over the study period, 14 children with established empyema as defined above were treated. The age range was 2-14 years (median 5 years), with seven boys and seven girls. The duration of fever before admission varied from 1 to 28 days (median 8 days). One further child with severe cerebral palsy was excluded.

\section{Microbiology}

Six of the 14 children had not received any antibiotic therapy before admission, and only in these six patients was a causative organism isolated. Blood culture was positive in four patients, cultures yielding Streptococcus pneumoniae in three children and Haemophilus influenzae in one. Pleural fluid culture was positive in two patients, one each growing Enterobacter and $\beta$ haemolytic streptococcus. The remaining eight children had received antibiotics for a period of 4-14 days (median 5 days) before admission and in these children no organism was isolated from either blood or pleural fluid.

\section{Initial imaging}

Chest radiographs at admission showed homogeneous opacity occupying more than $50 \%$ of the hemithorax in 11 of the 14 children. In 12 cases the empyema was left sided. Ultrasound scan was performed between 1 and 3 days after admission; in all cases thickening of both pleural surfaces, and strands crossing the pleural space causing loculation were seen.

\section{Management}

Intravenous antibiotics were given for 5-23 days (median 10 days). Chest tube was placed after ultrasound imaging under short general anaesthesia, between 1 and 6 days after admission (median 2 days).

\section{Clinical outcome}

Resolution of fever and constitutional symptoms occurred between 1 and 7 days after chest tube insertion (median 2 days). Duration of chest tube drainage was 4 to 14 days (median 8 days). Duration of hospital stay was 5 to 28 days (median 14 days). All patients were asymptomatic by the time of their initial follow up visit at 6 weeks.

On reviewing the case notes regarding the time lag between defervescence and chest tube removal, in some patients there was a period of up to 5 days, during which there was neither fever nor significant pleural fluid drainage, but the chest tube was left in place because of concern about the extensive pleural opacification on the chest radiograph.

\section{Radiological outcome}

At the time of discharge, all patients still showed marked pleural opacity occupying more than $50 \%$ of the hemithorax. Twelve had scoliosis (concave towards the affected hemithorax) detected on their chest radiograph.

The pleural opacity progressively resolved in all children without further intervention (see fig 1). The time taken for radiological resolution to occur (table 1) varied from 2 to 16 months. Two of the three patients who had delayed resolution (more than six months) of the opacity on chest $x$ ray examination underwent ventilation/perfusion lung scan, both with normal results. Scoliosis resolved in all patients in under six months.

\section{Lung function outcome}

Thirteen of the 14 children attended for lung function testing, between 3 and 24 months after discharge. Table 1 presents the results. Mean values are all close to predicted, and all individual children had results between $80 \%$ and $100 \%$ of predicted. 

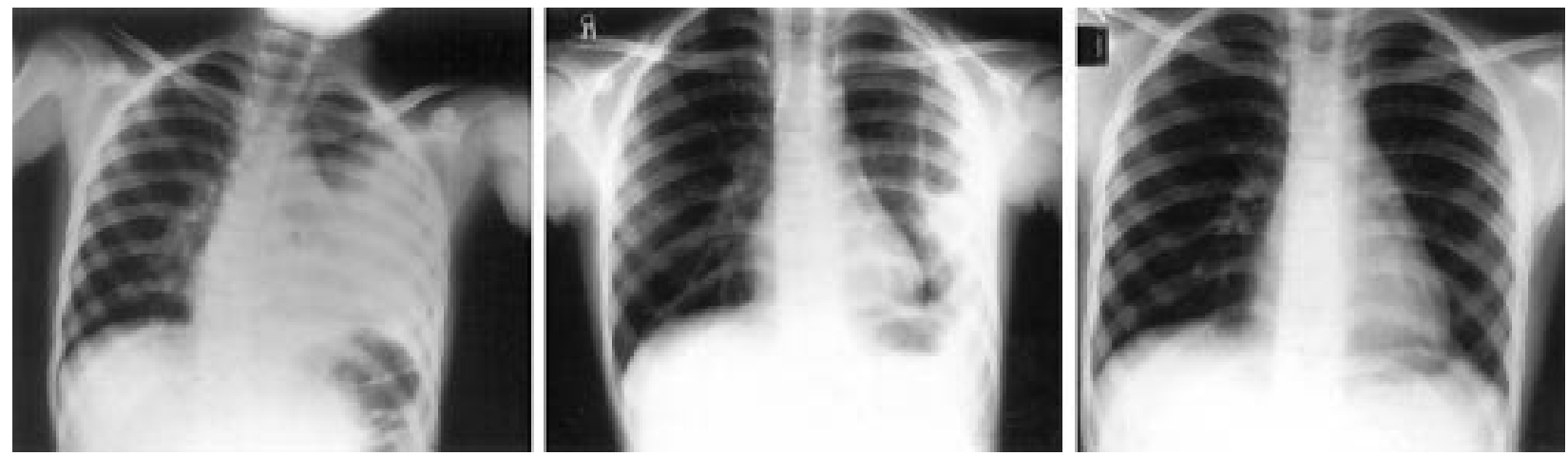

Figure 1 Sequence of chest radiographs in patient 5. Left to right: at discharge, and 6 weeks, and 6 months later.

\section{DISCUSSION}

In a consecutive series of 14 children admitted with established thoracic empyema and managed with early chest tube drainage and intravenous antibiotics, all made a full clinical recovery without resort to decortication. Fever and systemic symptoms resolved within seven days of chest tube insertion, despite persistence of extensive radiographic opacity. Full radiological resolution of the pleural "peel" occurred in all cases, without further treatment, and we could show no evidence of persisting lung function abnormality in any patient.

Considering first the acute picture and outcome, the characteristics of the children we studied are similar to those in other unselected series. The rate of isolation of organisms, and the pattern of pathogens seen, is similar to that of recent series, ${ }^{2822}$ with a predominance of streptococci (mainly $S$ pneumoniae) and Haemophilus, and different from series in the 1960s and 1970s when staphylococci predominated. ${ }^{16}{ }^{64}$ Fever in all our cases resolved within a week of chest tube drainage.

For long term outcome, our findings are broadly consistent with previous series which have followed children after empyema. ${ }^{121} 22$ Our study differs from the previous paediatric series in that by studying patients presenting over a relatively short period (just over two years) we were able to obtain a consistent approach to management which did not change over this period. This also contrasts with some series from tertiary centres, which included cases which had been managed for some time in the referring hospital without chest tube drainage or even thoracentesis. ${ }^{3}$ Unlike many other series, we had clear inclusion criteria, designed to produce a relatively homogeneous cohort. On the one hand, we excluded cases of simple parapneumonic effusion which would be expected to have a good outcome; on the other hand we excluded children with pre-existing problems who are likely to have unusual organisms (for example, anaerobes in handicapped children with aspiration).

In addition, we obtained complete radiological follow up and almost complete follow up of lung function. Of previous long term follow up studies, only two measured lung function. ${ }^{21}{ }^{22}$ Redding and colleagues ${ }^{22}$ reported follow up lung function on 15 children ( of 57 admitted with empyema during their 10 year sample period), only half of whom had required chest tubes, and none decortication. They found no evidence of restrictive disease: mean per cent predicted FVC (96\%) and TLC $(101 \%)$ were similar to our series. Mean FEV $(82 \%$ predicted) was lower, but at least one child had pre-existing asthma. McLaughlin and colleagues ${ }^{21}$ measured lung function in 10 children sampled from an unstated total number of empyema cases collected in Boston over 11 years. All the children they studied had required chest tubes, and two had also undergone decortication. Mean per cent predicted values were similar to our series ( $\mathrm{FEV}_{1}$ 90\%, FVC 92\%, TLC 92\%). They stated that five patients had a "mild restrictive defect", but they defined this as TLC one standard deviation below the population mean (equivalent to $89 \%$ predicted), and only one child had TLC less than $80 \%$ predicted.

In summary, we studied a sample of children from one institution, with a rigorous definition of empyema and a consistent (aggressive but non-surgical) approach to management, and achieved full follow up including lung function in over $90 \%$. We showed resolution of fever within seven days, marked radiological abnormality at discharge, but full return to normal $x$ ray and lung function at subsequent follow up.

Although this study does not resolve the controversy between early decortication and aggressive non-surgical management, it does provide an accurate picture of the outcome to be expected from the latter. Our results suggest that early chest tube placement, combined with high dose intravenous antibiotics, results in rapid fever resolution and good long term outcome without, in most cases, the need for decortication. This study was carried out before our participation in a multicentre study, which showed even more rapid resolution associated with the addition of intrapleural urokinase ${ }^{25}$ to this regime. Although proponents of early open decortication ${ }^{318}$ or thoracoscopic decortication ${ }^{11-14}$ have reported impressive results, none of these has included a randomised comparison with an aggressive non-surgical approach. At present, early resort to surgery appears difficult to justify without an appropriate multicentre randomised trial, which is urgently needed. Clinicians should beware of extrapolating adult empyema experience and practice to children, and of acting on the basis of radiological appearance rather than clinical progress.

\section{Authors' affiliations}

B Satish, M Bunker, P Seddon, Royal Alexandra Hospital for Sick Children, Brighton, UK

\section{REFERENCES}

1 Smith PL, Gerald B. Empyema in childhood followed roentgenographically: decortication seldom needed. Am J Roentgenol Radium Ther Nucl Med 1969;106:1 14-17

2 Chan W, Keyser-Gauvin E, Davis GM, et al. Empyema thoracis in children: a 26-year review of the Montreal Children's Hospital experience. J Pediatr Surg 1997:32:870-2.

3 Khakoo GA, Goldstraw P, Hansell DM, et al. Surgical treatment of parapneumonic empyema. Pediatr Pulmonol 1996;22:348-56.

4 American Thoracic Society. Management of non-tuberculous empyema. Am Rev Respir Dis 1962;85:935-6.

5 Freij BJ, Kusmiesz H, Nelson JD, et al. Parapneumonic effusions and empyema in hospitalised children: a retrospective review of 227 cases. Pediatr Infect Dis J 1984;3:578-91.

6 Béchamps GJ, Lynn HB, Wenzl JE. Empyema in children: review of Mayo clinic experience. Mayo Clin Proc 1970;45:43-50.

7 Lee-Chiong TL. Treating empyema without surgery. Postgrad Med 1997; 101:195-204.

8 Gocmen A, Kiper N, Toppare M, et al. Conservative treatment of empyema in children. Respiration 1993;60:182-5.

9 Rosen H, Nadkarni V, Theroux M, et al. Intrapleural streptokinase as adjunctive treatment for persistent empyema in pediatric patients. Chest 1998;103:1190-3. 
10 Krishnan S, Amin N, Dozor AJ, et al. Urokinase in the management of complicated parapneumonic effusions in children. Chest 1997; 112:1579-83

11 Stovroff $M$, Teague G, Heiss KF, et al. Thoracoscopy in the management of pediatric empyema. J Pediatr Surg 1995;30:1211-15.

12 Steinbrecher HA, Najmaldin AS. Thoracoscopy for empyema in children. J Pediatr Surg 1998;33:708-10.

13 Merry CM, Bufo AJ, Shah RS, et al. Early definitive intervention by thoracoscopy in pediatric empyema. J Pediatr Surg 1999;34:178-81.

14 Kern JA, Rodgers BM. Thoracoscopy in the management of empyema in children. J Pediatr Surg 2001;28:1128-32.

15 Foglia RP, Randolph J. Current indications for decortication in the treatment of empyema in children. J Pediatr Surg 1987;22:28-33.

16 Hoff SJ, Neblett WW, Heller RM, et al. Postpneumonic empyema in childhood: selecting appropriate therapy. J Pediatr Surg 1989:24:659-64.

17 Cham CW, Haq SM, Rahamim J. Empyema thoracis: a problem with late referral? Thorax 1993;48:925-7.
18 Carey JA, Hamilton JRL, Spencer DA, et al. Empyema thoracis: a role for open thoracotomy and decortication. Arch Dis Child 1998:79:510-13.

19 Mangete EDO, Kombo BB, Legg-Jack TE. Thoracic empyema: a study of 56 patients. Arch Dis Child 1993;69:587-8.

20 Hamm H, Light RW. Parapneumonic effusion and empyema. Eur Respir J 1997:10:1150-6.

21 McLaughlin FJ, Goldmann DA, Rosenbaum DM, et al. Empyema in children: clinical course and long-term follow-up. Pediatrics 1984;73:587-93

22 Redding GJ, Walund $L$, Walund $D$, et al. Lung function in children following empyema. Am J Dis Child 1990;144:1337-42.

23 Zapletal A Motoyama EK, van de Woestijne KP, et al. Maximum expiratory flow-volume curves and airway conductance in children and adolescents. J Appl Physiol 1969;26:308-16

24 Wise MB, Beaudry PH, Bates DV. Long-term follow-up of staphylococcal pneumonia. Pediatrics 1966;38:398-401.

25 Thomson $\mathbf{A H}$, Hull J, Kumar MR, et al. Randomised trial of intrapleural urokinase in the treatment of childhood empyema. Thorax 2002:57:343-7.

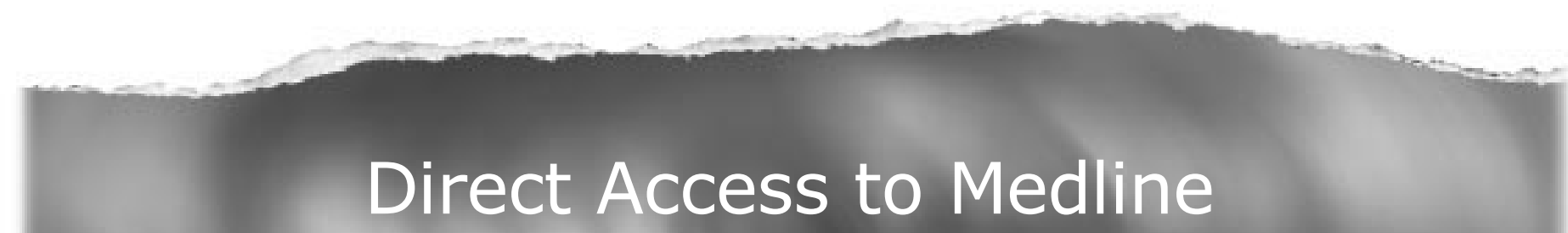

Medline

Link to Medline from the homepage and get straight into the National Library of Medicine's premier bibliographic database. Medline allows you to search across 9 million records of bibliographic citations and author abstracts from approximately 3,900 current biomedical journals.

www.archdischild.com 